\title{
Antioxidant dietary deficiency induces caspase activation in chick skeletal muscle cells
}

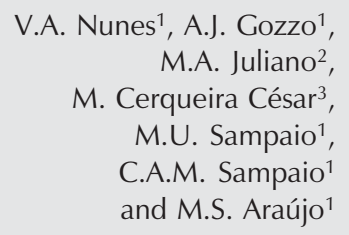

\author{
Departamentos de ${ }^{1}$ Bioquímica and ${ }^{2}$ Biofísica, Escola Paulista de Medicina, \\ Universidade Federal de São Paulo, São Paulo, SP, Brasil \\ ${ }^{3}$ Departamento de Ciências, Faculdade de Zootecnia e Engenharia de Alimentos, \\ Universidade de São Paulo, Pirassununga, SP, Brasil
}

\section{Correspondence \\ M.S. Araújo \\ Departamento de Bioquímica UNIFESP-EPM \\ Rua Três de Maio, 100, 6으 andar 04044-020 São Paulo, SP \\ Brasil \\ Fax: +55-11-5572-3006 \\ E-mail: mariana.bioq@unifesp.epm.br \\ Presented at SIMEC 2002 \\ (International Symposium \\ on Extracellular Matrix), \\ Angra dos Reis, RJ, Brazil, \\ October 7-10, 2002. \\ Research supported by FAPESP, CNPq and FADA (UNIFESP-SPDM).}

Received November 29, 2002 Accepted May 16, 2003

\begin{abstract}
Apoptosis and necrosis are two distinct forms of cell death that can occur in response to different agents and stress conditions. In order to verify if the oxidative stress induced by dietary selenium and vitamin $\mathrm{E}$ deficiencies can lead muscle cells to apoptosis, one-day-old chicks were reared using diets differing in their vitamin $\mathrm{E}(0$ or $10 \mathrm{IU} / \mathrm{kg}$ ) and selenium ( 0 or $0.15 \mathrm{ppm}$ ) supplementation. Chick skeletal muscle tissue was obtained from 28-day-old animals and used to verify apoptosis occurrence based on caspase activity detection and DNA fragmentation. Antioxidant deficiency significantly increased caspase-like activity assessed by the hydrolysis of fluorogenic peptide substrates (Abz-peptidyl-EDDnp) at $\lambda_{\mathrm{exc}}=320 \mathrm{~nm}$ and $\lambda_{\mathrm{em}}=420 \mathrm{~nm}$. Proteolytic activation was not accompanied by typical internucleosomal DNA fragmentation detected by field inversion gel electrophoresis. Although the general caspase inhibitor Nbenzyloxycarbonyl-Val-Ala-Asp(O-Me) fluoromethyl ketone (Z-VADfmk) ( 0 to $80 \mu \mathrm{M})$ did not block caspase-like activity when pre-incubated for $30 \mathrm{~min}$ with muscle homogenates, the hydrolyzed substrates presented the same cleavage profile in HPLC (at the aspartic acid residue) when incubated with the purified recombinant enzyme caspase-3. These data indicate that oxidative stress causes caspase-like activation in muscle cells and suggest that cell death associated with exudative diathesis (dietary deficiency of selenium and vitamin E) can follow the apoptotic pathway.
\end{abstract}

Cell death can follow two distinct pathways, necrosis or apoptosis. Necrosis appears to be the result of acute cellular dysfunction in response to severe conditions of stress or after exposure to toxic agents. It is characterized morphologically by a dramatic increase in cell volume followed by rupture of the plasma membrane. Apoptosis is a complex process characterized by cell shrinkage, chromatin condensation and internu-
Key words

- Oxidative stress

- Caspase activation

- Apoptosis

- Dietary selenium deficiency

- Dietary vitamin E deficiency

- Internucleosomal DNA

- Caspase substrate fragmentation cleosomal DNA fragmentation (1). The apoptotic program is the physiological form of cell death (2) that occurs during the development of multicellular organisms or in immune responses. Stress conditions, toxins, chemicals and physical agents including heat and radiation can also activate apoptosis.

Biochemical studies have shown that caspases, cysteine proteinases with specificity for aspartic acid, participate in programmed cell 
death (3). Based on $\mathrm{S}_{4}$ subsite preferences, caspases have been subdivided into three groups: I - caspase-1, -4 and -5 (YVADases), II - caspase-2, -3 and -7 (DEVDases) and III caspase-6, -8, -9 and -10 (IETDases), with preference for aromatic residues, aspartic acid and branched apolar residues, respectively, in the $\mathrm{P}_{4}$ position of substrates (4).

Reactive oxygen species (ROS) and the resulting oxidative stress have been implicated in both necrosis (5) and apoptosis (6), and the mode of cell death depends on various factors including the intensity of the initial stimulus (7). ROS involvement in apoptosis has been considered because high levels of oxidants or stress oxidative markers are present in apoptotic cells or cells undergoing apoptosis.

A recent report showed that pro-oxidant agents such as hydrogen peroxide, etoposide and semiquinones induce apoptosis and, in contrast, antioxidants suppress apoptosis by acting as ROS scavengers (6). These compounds are also involved in the generation of exudative diathesis in chicks, a pathology due to the combined dietary deficiency of the antioxidants selenium and vitamin $\mathrm{E}$, which results in lower growth and survival and degenerative lesions with varying degrees of necrosis in thigh and breast muscles (8-10).

In the present investigation, we used chick skeletal muscle cells in order to determine if apoptotic cell death can also be detected simultaneously with necrosis, and studied some molecular events involved in exudative diathesis.

Caspase activation and the pattern of DNA fragmentation were used as criteria to determine the occurrence of apoptosis and to differentiate between necrosis and apoptosis. Male chicks were obtained from a local hatchery and reared to 4 weeks of age in thermostatically controlled battery brooders. Food and water were provided ad libitum. Chicks were fed a semipurified basal diet based on isolated soy protein and cornstarch, according to the guidelines of the
National Academy of Sciences, National Research Council (1994). The basal diet contained $17 \mathrm{ng} / \mathrm{g}$ diet total selenium and vita$\min \mathrm{E}$ at levels of $5.7 \mu \mathrm{g} / \mathrm{g}$ diet. Chicks ( $\mathrm{N}=$ $150)$ were assigned randomly to two groups of 75 animals for each treatment (with $(+\mathrm{Se} /$ $+\mathrm{VE})$ or without (-Se/-VE) antioxidants). Vitamin E supplementation consisted of 10 $\mu \mathrm{g} / \mathrm{g}$ as $\mathrm{dl}-\alpha$-tocopheryl acetate and selenium consisted of $0.15 \mu \mathrm{g} / \mathrm{g}$ diet added as $\mathrm{Na}_{2} \mathrm{SeO}_{3}$. Animals were assessed daily for signs of exudative diathesis which included observation of the ability to walk, swelling of hock joints and poor feathering.

Chicks fed selenium- and vitamin E-deficient diets started to develop exudative diathesis at 17 days of age. The symptoms were those previously described $(9,10)$ and were characterized by a subcutaneous area of edema under the wings, breast and abdominal regions. After four weeks, animals were killed and the pectoralis muscle was removed and immediately frozen in liquid nitrogen for further experiments.

Most events in apoptosis appear to require a caspase-mediated proteolytic step. It was shown that the caspase cascade can be activated or amplified after cytochrome c release from the mitochondria into the cytosol during the early stages of apoptosis (11). Once cytochrome c is released, it leads to a series of protein-protein interactions that culminate in the activation of caspases (12). To determine if the cell death observed in exudative diathesis involves caspase activation, a fluorimetric assay was performed using cell extracts. Fragments ( $3 \mathrm{~g}$ ) of the pectoralis muscle were homogenized with a Potter homogenizer (Marconi, Piracicaba, São Paulo, SP, Brazil) in $30 \mathrm{ml}$ PBS, pH 7.4, containing $5 \mathrm{mM}$ EDTA, $10 \mu \mathrm{g} / \mathrm{ml}$ leupeptin, $10 \mu \mathrm{g} / \mathrm{ml}$ pepstatin A and $100 \mu \mathrm{M}$ phenylmethylsulfonyl fluoride (PMSF) on ice. Homogenates were centrifuged at $200 \mathrm{~g}$ at $4^{\circ} \mathrm{C}$. Cell pellets were washed with the same buffer and submitted to a second centrifugation step at $4^{\circ} \mathrm{C}$. Cell lysis was performed with $25 \mathrm{mM}$ 4-(2-hydroxyethyl)-piperazine- 
1-ethanesulfonic acid (HEPES) buffer, $\mathrm{pH}$ 7.5, 2 mM EDTA, and 0.5\% Triton X-100 with the same inhibitors for $20 \mathrm{~min}$ on ice.

Caspase-like activity was determined in cell lysates (100 $\mu \mathrm{g}$ protein) using the intramolecularly quenched substrates: AbzYVADNQ-EDDnp (I), Abz-DEVDNQEDDnp (II), Abz-IETDNQ-EDDnp (III), Abz-DEVDSVQ-EDDnp (IV), AbzDEVDGVQ-EDDnp (V), Abz-YEVDGVQEDDnp (VI), and Abz-VEIDNQ-EDDnp (VII), where Abz is $o$-aminobenzoic acid and EDDnp is N-2,4-dinitrophenylethylenediamine. Fluorimetric assays were carried out by the method of Vanags et al. (13) in 25 mM HEPES buffer, $\mathrm{pH}$ 7.5, 2 mM EDTA, 10 mM DTT, $10 \%$ sucrose, $0.1 \%$ 3-([3-cholamidopropyl] dimethylammonio)-1-propanesulfonate, $10 \mu \mathrm{g} / \mathrm{ml}$ pepstatin A, $10 \mu \mathrm{g} / \mathrm{ml}$ leupeptin, and $100 \mu \mathrm{M}$ PMSF (caspase activation buffer). Substrate $(10 \mu \mathrm{M})$ hydrolysis was monitored for $3 \mathrm{~h}$ at $37^{\circ} \mathrm{C}$ with a fluorimeter (TD-700, Turner Designs Instrument, Sunnyvale, CA, USA). Enzymatic activity is reported in arbitrary fluorescence units and the results obtained for experimental groups were compared using the Tukey test. $\mathrm{P}<$ 0.05 was taken as the level of significance. All determinations were done in triplicate in three independent experiments.

Caspase activity was characterized using the general caspase inhibitor N-benzyloxycarbonyl-Val-Ala-Asp(O-Me) fluoromethyl ketone (Z-VAD-fmk). Samples (75 $\mu \mathrm{g}$ protein) of muscle from both groups (+Se/+VE and $-\mathrm{Se} / \mathrm{VE}$ ) prepared as described above were incubated with caspase activation buffer for $15 \mathrm{~min}$ at $37^{\circ} \mathrm{C}$. Subsequently, increasing amounts of the inhibitor ( 0 to 80 $\mu \mathrm{M}$ ) were added and the mixtures were incubated for $30 \mathrm{~min}$ at $37^{\circ} \mathrm{C}$. The enzyme activity was measured on the basis of hydrolysis of the substrate Abz-DEVDNQ-EDDnp (10 $\mu \mathrm{M})$ at $\lambda_{\mathrm{exc}}=320 \mathrm{~nm}$ and $\lambda_{\mathrm{em}}=420 \mathrm{~nm}$ after $1,2,3$ and $5 \mathrm{~h}$ of incubation. The inhibitory efficiency of Z-VAD-fmk was tested on samples of purified recombinant caspase- 3 following the same procedure.

Detection of increased caspase-like activity (Figure 1A) in the group submitted to a selenium- and vitamin E-deficient diet suggests that nutritionally mediated oxidative stress induces caspase activation. In addition, it appears that caspases may be involved in the cell death observed in exudative diathesis, although the caspase activity detected in the -Se/-VE chick muscle was not reduced by the general caspase inhibitor Z-VAD-fmk even at a high concentration $(80 \mu \mathrm{M})$ (data not shown). However, there is some evidence that the apoptotic cell death can occur without effector caspases. Foghsgaard et al. (14) showed cathepsin B-mediated and caspase-independent apoptotic features in WEHI-S fibrosarcoma cells. Interestingly, it was also reported that the cell death process was increased by low but effective concentrations of a caspase inhibitor such as Z-VAD-fmk.

In order to confirm that the peptide substrates were hydrolyzed at the aspartic acid residue, as expected for caspases, and to further characterize the enzyme activity, cleaved bonds in substrates were determined by reverse-phase HPLC. Substrates $(5.0 \mu \mathrm{M})$ were incubated with recombinant caspase-3 or samples from chick muscle $(100 \mu \mathrm{g})$ in caspase activation buffer for approximately $2 \mathrm{~h}$ at $37^{\circ} \mathrm{C}$. Hydrolysis products were separated and identified using a $\mathrm{C}_{18}$ Beckman column $(5 \mu \mathrm{m}, 15$ x $4.6 \mathrm{~mm}$; Ultrasphere, Palo Alto, CA, USA) developed in $0.1 \%$ aqueous trifluoroacetic acid - solvent A with a linear gradient of acetonitrile - solvent $\mathrm{B}$ - for $20 \mathrm{~min}$ at a flow rate of $1.0 \mathrm{ml} / \mathrm{min}$ (gradient slope of $4 \% \mathrm{~B} / \mathrm{min}$ ). Elution profiles were obtained by recording absorbance at $365 \mathrm{~nm}$ with an absorbance detector (Shimadzu, SPD-6AV, Kyoto, Japan) and fluorescence at $\lambda_{\text {exc }}=320 \mathrm{~nm}$ and $\lambda_{\mathrm{em}}=420 \mathrm{~nm}$ with a fluorescence detector (Shimadzu, RF 535), which allowed the direct identification of EDDnp-containing peptides and Abz-Nterminal sequences, respectively. Controls 
were prepared without enzyme or cell lysate under the same conditions.

The retention times of the products were compared to those of the original peptides. The bonds cleaved were the same in the incubation with recombinant caspase- 3 or with cell lysates from muscle tissue (-Se/ $-\mathrm{VE}$ ) as identified by HPLC (Figure 1B). The pattern of substrate hydrolysis is an indication that enzyme activity in cell extracts is due to caspases. These enzymes show a high degree of specificity with an absolute requirement for cleavage after an aspartic acid residue and a recognition motif containing at least four amino acid residues $\mathrm{N}$-terminal to the cleavage site. This characteristic, which is exhibited by only one other eukaryotic protease, the serine protease granzyme $\mathrm{B}$, is important for the apoptotic process, since it involves cleavage of a particular group of proteins in an ordered manner rather than indiscriminate proteolysis (3).

Figure 1. A, Detection of caspase-like activity in cell lysates. Fluorimetric assays were performed in caspase buffer as described and substrate hydrolysis $(10 \mu \mathrm{M})$ was determined at $\lambda_{\mathrm{exc}}=320 \mathrm{~nm}$ and $\lambda_{\mathrm{em}}=420$ $\mathrm{nm}$ after $3 \mathrm{~h}$ (I, II and III) or $2 \mathrm{~h}$ (IV to VII) of incubation at $37^{\circ} \mathrm{C}$. Enzymatic activity was reported in arbitrary units of fluorescence (AUF) and compared between treatments by the Tukey test. Hydrolysis of all synthetic peptides was significantly higher in cell lysates of the -Se/-VE group $(P<0.05)$. B, Determination of the cleaved bonds. The substrate Abz-DEVDNQ-EDDnp (5.0 $\mu \mathrm{M})$ was incubated with purified caspase-3 or samples from the -Se/-VE group in caspase buffer. Fragments were resolved by HPLC in a linear acetonitrile gradient. The bonds cleaved $(\mathrm{DEVD} \downarrow N$ ) were the same in the incubation with caspase-3 or cell extract $(-\mathrm{Se} / \mathrm{VE})$ and are indicated by the arrow.

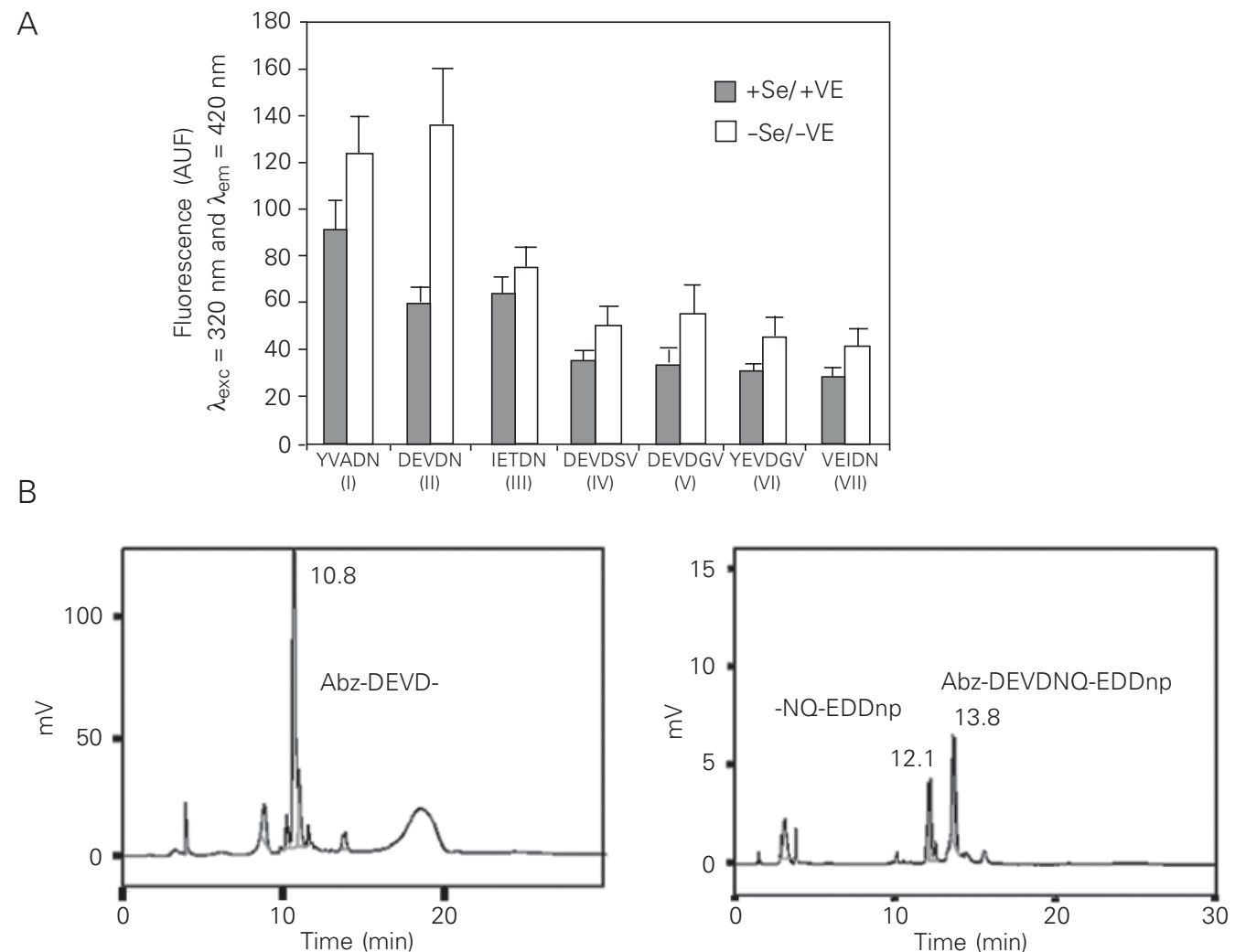

A histopathological hallmark of many progressive neuromuscular disorders is muscle fiber loss. While some types of muscular disorders clearly involve variable muscle fiber necrosis, which can be easily identified at the light microscopy level $(9,10)$, apoptotic cell death is much less evident in routine histological preparations. Progress has been made in the identification of apoptotic cells by DNA fragmentation and demonstration of up-regulation of apoptosis-associated factor such as proteins of the bcl-2 family and caspases. Nevertheless, the expression of some individual factor does not confirm the occurrence of apoptosis.

Detection of apoptotic cells in tissue sections currently relies on the terminal deoxynucleotidyl transferase dUTP nick end labeling (TUNEL) assay based on labeling singlestrand DNA breaks. However, even DNA fragmentation revealed by TUNEL may not be completely apoptosis-specific (15). Dem- 
onstration of DNA fragments by electrophoretic DNA laddering is a simple strategy for detecting cells undergoing apoptosis, although it requires DNA isolation.

For DNA fragment detection, samples obtained from muscle tissue ( $1 \mathrm{~g}$ ) were prepared and analyzed as described (16), with the following modifications: cells were lysed in $10 \mathrm{mM}$ Tris buffer, $\mathrm{pH} 8.0,2 \mathrm{mM}$ EDTA, $100 \mu \mathrm{M}$ PMSF and $2 \%$ SDS for $1 \mathrm{~h}$ at $42^{\circ} \mathrm{C}$, and centrifuged at 14,000 rpm for $20 \mathrm{~min}$. The supernatant was precipitated with $40 \mu \mathrm{l}$ of $2.5 \mathrm{M}$ acetate buffer, $\mathrm{pH} 5.2$, and 2 volumes of absolute ethanol at $-20^{\circ} \mathrm{C}$. Samples were incubated at $-20^{\circ} \mathrm{C}$ for $2 \mathrm{~h}$ and centrifuged at $2000 \mathrm{rpm}$. Pellets were added to 400 $\mu l$ of TE buffer $(10 \mathrm{mM}$ Tris and $1 \mathrm{mM}$ EDTA, pH 7.5) containing $0.5 \%$ sodium lauroyl sarcosine and $20 \mu \mathrm{g}$ RNAse. Samples were incubated for $1 \mathrm{~h}$ at $65^{\circ} \mathrm{C}, 150 \mu \mathrm{g}$ proteinase $\mathrm{K}$ was added and the preparation was incubated again at $37^{\circ} \mathrm{C}$. DNA was extracted with phenol:chloroform (3:1) and the mixtures were centrifuged at $6000 \mathrm{rpm}$. The aqueous phase was transferred to another tube and precipitated again with $2.5 \mathrm{M}$ acetate buffer, $\mathrm{pH} 5.2$, and 2 volumes of absolute ethanol, as previously described. Samples were incubated overnight at $-20^{\circ} \mathrm{C}$, centrifuged and the pellets were resuspended in TE buffer. DNA $(5 \mu \mathrm{g})$ was submitted to electrophoresis in $0.8 \%$ agarose gels, $0.5 \mu \mathrm{g} /$ $\mathrm{ml}$ ethidium bromide in $0.5 \mathrm{x}$ TBE buffer $(45$ $\mathrm{mM}$ Tris, $45 \mathrm{mM}$ boric acid, and $1.25 \mathrm{mM}$ EDTA, pH 8.0) at $40 \mathrm{~V}$ for $6 \mathrm{~h}$. DNA bands were visualized with a UV transilluminator. Samples for the detection of high molecular weight DNA fragments were prepared as described (17). Field inversion gel electrophoresis was run at $180 \mathrm{~V}$ in $1 \%$ agarose gels in $0.5 \mathrm{x}$ TBE buffer at $12^{\circ} \mathrm{C}$, with the ramping rate changing from $0.8 \mathrm{~s}$ to $30 \mathrm{~s}$ during a $24-$ $\mathrm{h}$ period, and a 3:1 forward to reverse ratio being applied. DNA was stained with ethidium bromide $(0.5 \mu \mathrm{g} / \mathrm{ml})$, visualized at 305 $\mathrm{nm}$ by UV light and photographed with a scanner (Fuji, Tokyo, Japan).
Oligonucleosomal DNA fragments were undetectable in both the -Se/-VE and +Se/ + VE groups, and apparently high molecular weight fragments either remained in the well or migrated slowly into the gel as a single band by conventional electrophoresis. These fragments (approximately $50 \mathrm{~kb}$ in size) were barely resolved by field inversion gel electrophoresis, as shown in Figure 2.

Although the formation of the DNA ladder has been used as a biochemical indicator of apoptosis, it is, in fact, only the end point of DNA degradation and does not reflect the full pattern of DNA fragmentation occurring during apoptosis. Indeed, many cells do not degrade their DNA to this extent. A recent report has shown DNA degradation during apoptosis to be a much more complex process that begins with the generation of high molecular weight DNA fragments, which
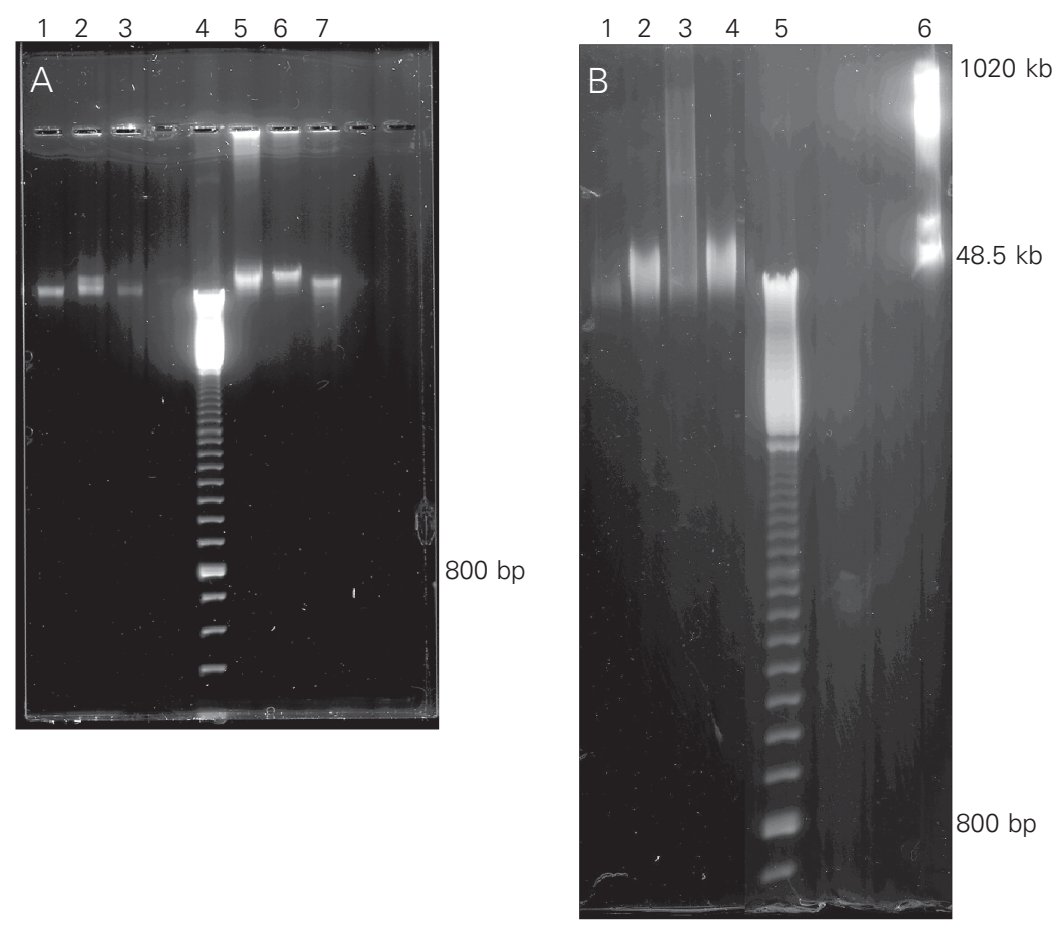

Figure 2. Separation of muscle cell. A, Conventional agarose gel electrophoresis was performed in $0.8 \%$ agarose gels at $40 \mathrm{~V}$ for $6 \mathrm{~h}$. Lanes 1, 2 and 3: sample +Se/+VE; lane 4: 100-bp ladder (molecular mass marker); lanes 5, 6 and 7: samples -Se/-VE. B, Field inversion gel electrophoresis was run at $180 \mathrm{~V}$ in $1 \%$ agarose gels. Lanes 1 and 3 : sample +Se/+VE; lanes 2 and 4: sample -Se/-VE; lane 5: 100-bp ladder; lane 6: lambda ladder pulsed field gel marker $(48.5$ to $1020 \mathrm{~kb}$ ). The sizes of the markers are indicated at the right of each figure 
are undetectable by conventional electrophoresis. We have adapted a form of field inversion gel electrophoresis to optimize the separation of DNA fragments eventually produced in muscle cells under stressful conditions, since a prerequisite for the analysis of high molecular weight DNA is the elimination of mechanical or enzymatic damage to the DNA during the processing of cells. Even using modified procedures, we did not observe the hallmark profile of DNA fragmentation in the samples of muscle tissue. According to some investigators, DNA fragmentation is not a requirement in programmed cell death, but rather, can be a late and nonessential event (18). In addition, nucleases involved in DNA degradation have been demonstrated mostly by indirect evidence.

It has been previously mentioned that little is known about the initiating events and factors involved in apoptotic cell death, in particular in skeletal muscle. While apoptosis plays an important role in the physiological turnover of cells and tissues, necrosis is usually confined to pathologic states. How- ever, there is increasing evidence now that necrosis and apoptosis may share certain common factors and pathways, which include death domain receptors, mitochondrial permeability transition pores or mitochondrion-nuclear translocation of the apoptosis initiating factor (19). Also, apoptosis of multinucleated muscle fibers in which successive fiber segments are controlled by individual nuclei may be different from that seen in mononucleated cells. It has been shown that not all nuclei of a muscle fiber might display DNA fragmentation at the same time (20). Apoptosis of individual myonuclei and the subsequent degradation of the associated sarcoplasmic segment probably contribute to the process of muscle fiber atrophy, which may occur after denervation.

These reports support the observation that the oxidative stress responsible for exudative diathesis symptoms in chick muscle can also lead to caspase activation and ultimately to apoptosis, although most molecular events involved in the process still remain unclear.

\section{References}

1. Orrenius S, McConkey DJ, Bellomo G \& Nicotera P (1989). Role of $\mathrm{Ca}^{2+}$ in toxic cell killing. Trends in Pharmacological Sciences, 10: 281-285

2. Kerr JFR, Wyllie AH \& Currie AR (1972). Apoptosis: a basic biological phenomenon with wide-ranging implications in tissue kinetics. British Journal of Cancer, 26: 239-257.

3. Cryns V \& Yuan J (1998). Proteases to die for. Genes and Development, 12: 1551-1570.

4. Nicholson DN \& Thornberry NA (1997). Caspases: killer proteases. Trends in Biochemical Sciences, 22: 299-306.

5. Disatnik MH, Dhawan J, Yu Y, Beal MF, Whirl MM, Franco AA \& Rando TA (1998). Evidence of oxidative stress in $\mathrm{mdx}$ mouse muscle: studies of the pre-necrotic state. Journal of Neurological Sciences, 161: 77-84.

6. Jabs T (1999). Reactive oxygen intermediates as mediators of programmed cell death in plants and animals. Biochemical Pharmacology, 57: 231-245.

7. Bonfoco E, Krainc D, Ankarcrona M, Nicotera P \& Lipton SA (1995). Apoptosis and necrosis: two distinct events induced, respectively, by mild and intense insults with $\mathrm{N}$-methyl-d-aspartate or nitric oxide/superoxide in cortical cell cultures. Proceedings of the National Academy of Sciences, USA, 92: 7162-7166.
8. Hassan S, Hakkarainen J, Jönsson L \& Työppönen J (1990). Histopathological and biochemical changes associated with selenium and vitamin E deficiency in chicks. Journal of Veterinary Medicine, A37: 708-720

9. Bartholomew A \& Latshaw DE (1998). Changes in blood chemistry, hematology, and histology caused by selenium/vitamin E deficiency and recovery in chicks. Biological Trace Element Research, 62: 716.

10. Avanzo JL, Mendonça CX, Pugine SMP \& Cerqueira-César M (2001). Effect of vitamin $E$ and selenium on resistance to oxidative stress in chicken superficial pectoralis muscle. Comparative Biochemistry and Physiology. Part C, Pharmacology, Toxicology and Endocrinology, 129: 163-173.

11. Kluck RM, Bossy-Wetzel E, Green DR \& Newmeyer DD (1997). The release of cytochrome $\mathrm{c}$ from mitochondria: a primary site for $\mathrm{Bcl}-2$ regulation of apoptosis. Science, 275: 1132-1136.

12. Li PD, Nijhawan D, Budihardjo I, Srinivasula SM, Ahmad M, Alnemri ES \& Wang X (1997). Cytochrome $c$ and dATP-dependent formation of Apaf-1/caspase-9 complex initiates an apoptotic protease cascade. Cell, 91: 479-489.

13. Vanags DM, Porn-Ares MI, Coppola S, Burgess DH \& Orrenius $S$ (1996). Protease involvement in fodrin cleavage and phosphatidyl- 
serine exposure in apoptosis. Journal of Biological Chemistry, 271: 31075-31085.

14. Foghsgaard L, Wissing D, Mauch D, Lademann U, Bastholm $L$, Boes M, Elling F, Leist M \& Jaattela M (2001). Cathepsin B acts as a dominant execution protease in tumor cell apoptosis induced by tumor necrosis factor. Journal of Cell Biology, 153: 999-1009.

15. Dawson BA \& Lough J (1988). Immunocytochemical localization of transient DNA strand breaks in differentiating myotubes using in situ nick-translation. Developmental Biology, 127: 362-367.

16. Walker PR, Leblanc J, Smith B, Pandey S \& Sikorska M (1999). Detection of DNA fragmentation and endonucleases in apoptosis. Methods: A Companion to Methods in Enzymology, 17: 329-338.

17. Cebers G, Zhivotovsky B, Ankarcrona M \& Liljequist S (1997). AMPA neurotoxicity in cultured cerebellar granule neurons: mode of cell death. Brain Research Bulletin, 43: 393-403.

18. Fimia GM, Gottifredi V, Passananti C \& Maione R (1996). Doublestranded internucleosomal cleavage of apoptotic DNA is dependent on the degree of differentiation in muscle cells. Journal of Biological Chemistry, 271: 15575-15579.

19. Denecker G, Vercammen D, Declercq W \& Vandenabeele P (2001). Apoptotic and necrotic cell death induced by death domain receptors. Cellular and Molecular Life Sciences, 58: 356-370.

20. Huppertz B, Tews DS \& Kaufmann P (2001). Apoptosis and syncytial fusion in human placental trophoblast and skeletal muscle. International Review of Cytology, 205: 215-253. 